\title{
Código de Ética dos Profissionais de Enfermagem: uma pesquisa documental
}

Recebido em: 16/11/2011

Aceito em: 16/04/2012
Rudval Souza da Silva

Denize Timóteo dos Santos ${ }^{2}$

Sueli da Silva de Carvalho ${ }^{2}$

Ângela Carla Ferraz de Novaes Lisboa²

Esta pesquisa documental teve como objetivo comparar e analisar o Código de Ética dos Profissionais de Enfermagem (Cepe) da primeira à atual versão. Foram analisadas as resoluções do Conselho Federal de Enfermagem que aprovaram o Cepe. Análise comparativa dos capítulos referentes a cada uma das versões do Cepe. Tornou-se mais clara a abrangência do Código de Ética, contemplando de modo mais específico aspectos como a pesquisa com seres humanos e determinando, assim, as condutas éticas relacionadas aos direitos, deveres e responsabilidade pelo cuidado com a pessoa, família e comunidade.

Descritores: Códigos de Ética, Ética Profissional, Ética em Enfermagem.

\section{Code of Ethics for Nursing Professional: a document study}

This documental study aimed to compare and analyze the Code of Ethics of Professional Nursing (CENP) since the first until the current version. It was analyzed the resolutions of the Nursing Federal Council which approved the CENP. Comparative analysis of the chapters referring to each version of CENP. The results showed significant changes in CEPN. Its structure has become clearer, the scope of the Code of Ethics, looking more specifically at issues such as research with human beings, determining ethical conduct related to rights, duties and responsibility for the care of the person, family and community.

Descriptors: Codes of Ethics, Ethics Professional, Ethics Nursing.

\section{Código de Ética de los Profesionales de Enfermería: un estudio documental}

El objetivo de este estudio documental fue comparar y analizar el Código de Ética de los Profesionales de Enfermería (CEPE) de la primera a la versión actual. Analizaronse las resoluciones del Consejo Federal de Enfermería, que aprobó la CEPE. Análisis comparativo de los capítulos de cada una de las versiones de la CEPE. Los resultados mostraron cambios significativos en la CEPE, ya que su estructura ha quedado más clara, el alcance del Código de Ética, más específicamente, temas como la investigación con seres humanos, con lo cual la determinación de la conducta ética en relación con derechos, deberes y la responsabilidad del cuidado de la persona, familia y comunidad.

Descriptores: Códigos de Ética, Ética Profesional, Ética en Enfermería.

\section{INTRODUÇÃO}

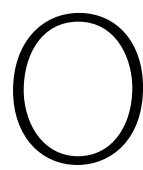
Código de Ética Profissional pode ser definido como um conjunto de normas, direitos e princípios morais que servem como fundamentos para orientar o exercício de determinada profissão, a partir de padrões de condutas que representam o que se espera de uma determinada classe profissional. Cada profissão elabora seu código objetivando fornecer subsídios para o agir e o pensar do profissional, além de prover informações que visam à proteção do profissional, sua categoria e todos que dela dependem. Em alguns Códigos de Ética Profissional estão contempladas as infrações e penalidades que devem ser imputadas aos que não cumprirem os preceitos éticos e legais no âmbito de sua atuação profissional ${ }^{(1,2)}$.

Assim sendo, e considerando a obrigatoriedade de todos os profissionais de se inscreverem em seu órgão de classe para que seu exercício profissional seja considerado legalizado, os órgãos de classe têm o poder de determinar sanções àqueles que violarem os preceitos éticos aprovados no Código de Ética Profissional ${ }^{(2)}$.

No contexto da enfermagem, o Código de Ética Profissional recebe atualmente a denominação de Código de Ética dos Profissionais de Enfermagem (Cepe) e tem por objetivo estabelecer parâmetros relacionados aos direitos, proibições, deveres e responsabilidades para o exercício da enfermagem frente às relações profissionais no contexto do cuidado com a pessoa, família e comunidade, as relações com a equipe interdisciplinar, com as organizações da categoria e organização empregadora, o sigilo profissional, o ensino, a pesquisa e a produção técnico-científica e a publicidade, além de estabelecer as infrações e penalidades, independentemente da atuação, na assistência, no ensino, na pesquisa ou no gerenciamento, de modo que todos os profissionais de enfermagem conheçam e façam cumprir os preceitos éticos contidos no Cepe ${ }^{(1)}$.

Historicizando a trajetória dos códigos de ética no âmbito da enfermagem, identifica-se que o primeiro código de ética da

1 Enfermeiro. Mestre e doutorando em enfermagem pela Escola de Enfermagem da Universidade Federal da Bahia (UFBA). Conselheiro do Coren-BA (2008-2011). Bolsista da Capes. Professor assistente do curso de enfermagem da Unime/Lauro de Freitas, Bahia. Email: rudvalsouza@yahoo.com.br

2 Acadêmicas do sétimo semestre do curso de enfermagem da Unime/Lauro de Freitas, Bahia. 
enfermagem em nível internacional recebeu a denominação de Código de Ética para Enfermeiras e foi aprovado pelo Conselho Internacional de Enfermeiras (CIE) em 1953, num evento ocorrido no Brasil, em reunião durante o Congresso Quadrienal de Enfermagem do CIE. A partir de então, líderes da enfermagem brasileira deram os primeiros passos para a elaboração do Código de Ética da Enfermagem no contexto nacional ${ }^{(1,3)}$.

Os primeiros estudos para a elaboração de um código de ética para a enfermagem brasileira foram realizados pela Associação Brasileira de Enfermagem (ABEn) e seus resultados, publicados em 1958. Essa versão continha 16 artigos, mantendo os padrões éticos relacionados às demais profissões da saúde, porém dando ênfase a expressões como dedicação, discrição, lealdade e confiança, considerando as peculiaridades da enfermagem. Ela sofreu uma reformulação em 1975 pela própria $A B E n$, sendo acrescidos dois artigos. Passou a contar com 18 artigos no total, mas sem mudar seus fundamentos ${ }^{(1)}$.

Apesar de todos os esforços da ABEn para discutir, elaborar e propor elementos para a estruturação do código de ética, ela não tem competência legal para legislar e, principalmente, para obrigar os profissionais de enfermagem a respeitar os preceitos éticos do código. Cabe-lhe apenas sugerir e recomendar seu cumprimento, considerando sua competência, que se volta para a promoção de atividades científico-culturais e políticas ${ }^{(1,3)}$.

No entanto, diante de sua abrangência de atuação e trajetória de lutas, a ABEn empreendeu ações que culminaram na criação do Sistema Conselho Federal e Conselhos Regionais de Enfermagem, órgãos que de fato receberam a competência legal para a elaboração e fiscalização do cumprimento do Código de Ética(4).

A lei $5905 / 73^{(4)}$ que cria o Sistema Conselho Federal e Conselhos Regionais de enfermagem diz, em seu art. $8^{\circ}-$ inciso III, que compete ao Conselho Federal a elaboração do Código de Deontologia de Enfermagem e a realização de suas alterações, quando se fizer necessário, ouvindo os Conselhos Regionais, competência essa que já foi exercida por quatro vezes, considerando que o Código de Ética dos Profissionais de Enfermagem se encontra atualmente em sua quarta versão.

Portanto, com a criação do Sistema Conselho Federal e Conselhos Regionais de enfermagem, deu-se continuidade a estudos realizados por profissionais de enfermagem que integravam a ABEn acerca do código de ética e, em conjunto com o Conselho Federal de Enfermagem, o qual dispõe de competência legislativa, aprovou em 1975, através da resolução Cofen $n^{\circ}$ 09/1975, o primeiro código que recebeu o nome de Código de Deontologia de Enfermagem. Vale ressaltar que essa resolução só foi publicada no Diário Oficial da União um ano depois, em 29 de março de 1976, motivo pelo qual é comum encontrar publicações citando 1975 e outras 1976 como o ano da criação do primeiro Código de Deontologia de Enfermagem ${ }^{(1,3)}$.

Esse código já passou por três reformulações, sendo a última aprovada pelo Cofen pela resolução 311/2007, com data de 12 de maio de 2007.

Dessa maneira, entendendo a relevância do Código de Ética Profissional para os profissionais de enfermagem e a importância de conhecer o contexto histórico em que se insere o Cepe, o presente estudo constitui-se numa pesquisa documental que teve como objetivo comparar e analisar o Código de Ética dos Profissionais de Enfermagem (Cepe) da primeira à atual versão, buscando identificar suas modificações e conquistas

\section{METODOLOGIA}

Estudo caracterizado como pesquisa exploratória descritiva, do tipo análise documental, que tem por finalidade fornecer ao investigador possibilidades de reunir grande quantidade de informações a respeito de determinada legislação ${ }^{(5)}$.

A escolha da metodologia de análise documental possibilitou o processo de pesquisa, confrontação entre as versões do Cepe e análise dos resultados. Esse estudo foi organizado a partir de um protocolo constando das etapas: seleção das versões do Cepe; representação da amostra em formato de tabela, levando-se em consideração cada edição e a correlação entre os artigos de cada versão do Cepe e as características comuns; apresentação dos resultados identificando as modificações nos capítulos, as mudanças estruturais e as conquistas para os profissionais de enfermagem, com as atualizações do Cepe.

O levantamento das versões do Cepe foi realizado na Biblioteca do Conselho Regional de Enfermagem da Bahia por meio da série de Documentos Básicos do Cofen ${ }^{(6-8)}$ e no portal do Conselho Federal de Enfermagem ${ }^{(9)}$.

\section{RESULTADOS E DISCUSSÃO}

O Código de Ética é definido como um conjunto de normas que, por força de lei, determina quais são os direitos e deveres de um grupo profissional em relação a suas atribuições e responsabilidades ${ }^{(3)}$.

O CEPE que passou por mudanças objetivando o aprimoramento da qualidade do exercício profissional da enfermagem, pauta-se nos princípios da dignidade humana nas dimensões biopsicossocioespirituais e tem por finalidade nortear o exercício da enfermagem, devendo todos os profissionais de enfermagem pautar suas condutas profissionais a partir do que rege o Cepe. Assim sendo, conforme preceitua a lei 5905/1973, os profissionais de enfermagem são fiscalizados pelo Conselho Federal e Conselhos Regionais de Enfermagem em relação ao cumprimento do que determina o Cepe.

O primeiro código de ética proposto para os profissionais da enfermagem brasileira surgiu em 1958, por iniciativa da Associação Brasileira de Enfermagem (ABEn), que, embora não tivesse competência legislativa e executiva para aprovar e fazer cumprir o código de ética pela classe de profissionais de enfermagem, criou o citado código de ética, restringindo-se a 
apenas recomendar e sugerir seu cumprimento ${ }^{(1,3)}$.

O primeiro código publicado em 1958 pela ABEn possuía 16 artigos e tinha como princípio básico para os profissionais de enfermagem servir a pessoa humana, zelando pela conservação da vida, aliviando o sofrimento e promovendo a saúde, em conjunto com os demais membros da equipe de saúde, respeitando a vida humana em todas as circunstâncias, desde a concepção até a morte. O referido código se diferenciava dos de outras profissões da época, na ênfase que era dada à dedicação, discrição, lealdade e confiança como qualidades exigidas das enfermeiras, considerando que, naquela época, não existiam as demais categorias profissionais da enfermagem ${ }^{(3)}$. Esse código foi reformulado em 1975 pela própria $A B E n$, mantendose as premissas básicas, porém acrescentando-se dois artigos. Continuava, porém, sem valor legal, impedindo que fosse cobrado seu cumprimento, pois funcionava apenas como um texto de autorregulamentação(1,3).

Com a criação do Sistema Conselho Federal e Conselhos Regionais de Enfermagem em 1973, a partir da lei 5905, surgiu então o órgão com competência para elaborar e fiscalizar o cumprimento do código de ética, podendo, inclusive, alterá-lo quando necessário. Daí advém o primeiro código de ética oficial para os profissionais da enfermagem brasileira, baseado no código de ética criado pela $A B E n$ em 1958, tendo, em sua versão inicial, a denominação de Código de Deontologia de Enfermagem. Isso porque trazia em seu preâmbulo características relacionadas ao cumprimento dos deveres enquanto princípios que norteiam o homem e sua trajetória existencial, além de considerar que, quando o ser humano se apresenta sob as vestes de um profissional, os deveres são normas de condutas que orientam o exercício de suas atividades, nas relações profissionais entre si, com a pessoa e com a comunidade. Percebe-se que não se trata em nenhum momento dos direitos profissionais, mas tão-somente dos deveres atribuídos aos profissionais de enfermagem ${ }^{(4,6)}$.

Como órgão disciplinador e fiscalizador do exercício profissional da enfermagem, o Cofen passa a cobrar o cumprimento do que está determinado no presente Código de Deontologia de Enfermagem, que foi aprovado pela resolução Cofen 09, com data de 4 de outubro de 1975, porém somente publicada no Diário Oficial da União no ano seguinte. Quando da fiscalização profissional frente ao que determinava a presente resolução - Código de Deontologia de Enfermagem -, o Cofen tinha autoridade para impor penalidades cabíveis, as quais eram atribuídas aos profissionais que infringissem o Código de Deontologia de Enfermagem(6).

Em relação às infrações e penalidade, essas eram atribuídas àqueles que não cumprissem o Código de Deontologia de Enfermagem, mas naquela época havia uma resolução do
Cofen que aprovava normas específicas para caracterizar uma infração ética e suas penalidades, qual seja, a resolução Cofen 51 , de 24 de março de 1979(10). Atualmente, não existe mais uma resolução específica para tratar de infrações e penalidade. Desde a segunda atualização do código de ética, a resolução Cofen 51 foi revogada e os aspectos referentes a infrações e penalidades passaram a fazer parte do Código de Ética dos Profissionais de Enfermagem ${ }^{(7)}$.

O primeiro código de ética, denominado Código de Deontologia de Enfermagem - resolução Cofen 09/1975, era constituído de 28 artigos distribuídos em cinco capítulos, a saber: responsabilidades fundamentais; o exercício profissional; o enfermeiro perante a classe; o enfermeiro perante os colegas e demais membros da equipe de saúde; e um último capítulo acerca das disposições gerais ${ }^{(6)}$.

O primeiro capítulo dessa versão tratava exclusivamente das atribuições e do papel do enfermeiro, preconizando uma assistência de enfermagem direcionada para o indivíduo, a família e a comunidade, com medidas relacionadas com a promoção, proteção, recuperação da saúde, prevenção de doenças e reabilitação de incapacitados, em busca do alívio do sofrimento e do desenvolvimento de um ambiente terapêutico.

O segundo capítulo, que contemplava o maior número de artigos - 11 -, fazia referência ao exercício profissional e tratava de definir deveres e proibições direcionados ao enfermeiro. Apresentava, ainda, algumas afirmações do que se esperava do profissional enfermeiro. Importante ressaltar que naquela época já havia uma preocupação com o processo de cuidar sistematizado, considerando a presença de artigos que abordavam as atribuições do enfermeiro na realização dos diagnósticos das necessidades de enfermagem do paciente, a fim de elaborar o plano de cuidados e a execução das prescrições de enfermagem.

Havia apenas um artigo que mencionava os direitos do enfermeiro, tratando do direito à justa remuneração por seu trabalho.

O que chama a atenção nesse texto é seu direcionamento exclusivamente para o enfermeiro, não havendo direcionando algum para os demais integrantes da enfermagem, levandose em conta que, historicamente, sabe-se que existiam os atendentes de enfermagem. Porém, a esses não era atribuído o dever de cumprir o Código de Deontologia de Enfermagem, dando margem à interpretação de que apenas os enfermeiros deveriam cumprir os deveres e responsabilidades contidos naquele código.

Em 1993, o Código de Deontologia de Enfermagem sofreu sua primeira modificação, com a aprovação da resolução Cofen 160, de 12 de maio de $1993^{(7)}$. Essa nova versão do código de ética foi alvo de significantes modificações já a partir do 
título. Antes, era denominado Código de Deontologia de Enfermagem, e passou a ser chamado de Código de Ética dos Profissionais de Enfermagem (Cepe). Sofreu ainda mudanças estruturais, inclusive com a exclusão do preâmbulo, que constava na primeira versão e nessa nova ganha um capítulo exclusivo, tratando dos princípios fundamentais inerentes ao exercício da enfermagem, na forma de artigos. Também cresceu o número de artigos, que passou dos 28 da versão anterior para 100, distribuídos em nove capítulos.

Em relação à modificação relacionada ao título, que passou para Código de Ética dos Profissionais de Enfermagem (Cepe) e não mais Código de Deontologia, essa pode ser atribuída à abrangência tomada pelo novo código, com inclusão de capítulo específico no tratamento dos direitos dos profissionais de enfermagem, haja vista que a deontologia determina apenas o que é vetado e quais são os deveres inerentes a cada profissão, não cabendo tratar dos direitos relativos aos profissionais ${ }^{(2)}$.

O Código de Ética dos Profissionais de Enfermagem - resolução Cofen 160/1993 - passou a contemplar 100 artigos distribuídos em nove capítulos, a saber: princípios fundamentais; direitos; responsabilidades; deveres; proibições; deveres disciplinares; infrações e penalidades; aplicação das penalidades; e um último capítulo acerca das disposições gerais ${ }^{(7)}$.

Uma modificação significativa observada nessa versão está relacionada ao tratamento direcionado a todos os profissionais de enfermagem e não apenas aos enfermeiros, como na versão anterior.

Nessa nova versão do Cepe, observou-se que não contempla o preâmbulo, fato para oqual não foi encontrada nenhumajustificativa; pode-se perceber que o capítulo que tratava das responsabilidades fundamentais passou a ser definido como princípios fundamentais. Contemplou-se a presença de capítulos com seus respectivos artigos, tratando de modo específico dos direitos, responsabilidades, deveres, proibições e deveres disciplinares.

A resolução 160/1993, que aprovou a nova versão do Cepe, revogou a resolução 51/1979 e passou a considerar, no bojo do código de ética, a caracterização das infrações éticas e disciplinares, as penalidades e suas aplicações, a serem impostas pelos Conselhos Federal e Conselhos Regionais de Enfermagem àqueles que não observarem ou deixarem de cumprir o que determina o Cepe.

Em 2000, o Código de Ética dos Profissionais de Enfermagem passou por uma única reformulação, com a exclusão apenas de um artigo entre os 100 da edição anterior. Essa modificação foi aprovada pela resolução Cofen 240/2000. A estrutura do Cepe ficou a mesma, contando apenas com a supressão do artigo 69, que tratava da publicidade de medicamentos, passando a ter, a partir de então, 99 artigos no total.

Possivelmente, com a ampliação do campo de atuação do profissional enfermeiro na divulgação de produtos de uso hospitalar, a plenária do Cofen tenha revisto e excluído o artigo que proibia aos profissionais de enfermagem fazer publicidade de medicamentos ou outro produto farmacêutico, instrumental, equipamento hospitalar, valendo-se de sua profissão, considerando-se que atualmente esse é um campo de atuação para o profissional enfermeiro.

Em 2006, iniciaram-se estudos e seminários para que fosse realizada uma nova modificação no Cepe diante dos avanços científicos e culturais, o que suscitaram em novos dilemas éticos. Desse modo, em 8 de fevereiro de 2007, foi publicada a resolução Cofen n³ 311/2007, que aprovou a nova reformulação do Código de Ética dos Profissionais de Enfermagem. Contudo, essa resolução só entrou em vigor em 12 de maio do mesmo ano, data em que se iniciaram as comemorações da Semana de Enfermagem no Brasil, entre 12 e 20 de maio.

Nessa última reformulação, as mudanças foram bem maiores em relação às anteriores, a começar pelo número de artigos, que passaram de 99 para 132, distribuídos em sete capítulos.

O Código de Ética dos Profissionais de Enfermagem resolução Cofen 311/2007 - passou a contemplar 132 artigos, distribuídos em sete capítulos, a saber: princípios fundamentais; das relações profissionais; do sigilo profissional; do ensino, da pesquisa e da produção técnico-científica; da publicidade; das infrações e penalidades; aplicação das penalidades; e um último capítulo acerca das disposições gerais. Vale ressaltar que o capítulo se subdivide em quatro seções, a saber: das relações com a pessoa, família e coletividade; das relações com os trabalhadores de enfermagem, saúde e outros; das relações com as organizações da categoria; das relações com as organizações empregadoras ${ }^{(9)}$.

Com a revisão do presente código, é possível observar que a atual versão do Cepe contempla aspectos até então negligenciados nas demais versões do código de ética. Como exemplo, pode ser citada a questão do ensino e da pesquisa com seres humanos, que, a partir da resolução 311/2007, passou a contar com um capítulo tratando exclusivamente dessa temática.

A partir dessa versão, o Cepe passou a contar com um preâmbulo que traz uma definição da profissão de enfermagem e a contextualiza em toda a trajetória da reformulação do código de ética, além de mencionar as bases referenciais, como a Declaração Universal dos Direitos do Homem, a resolução 196/1996 do Conselho Nacional de Saúde - Ministério da Saúde, entre outras.

Nesse aspecto, vale mencionar que há autores ${ }^{(1)}$ que tecem críticas a algumas não-conformidades no texto do preâmbulo, tais como: a Declaração Universal dos Direitos Humanos não pode ter sido "promulgada pela Assembleia Geral das Nações Unidas", pois esse verbo indica hierarquia, que não existe em uma organização internacional em que todas as nações, membros da ONU, são igualmente soberanas. O verbo correto, segundo os autores ${ }^{(1)}$, seria "proclamada ou aclamada", mas não promulgada. Sobre a Declaração de Helsinque, adotada inicialmente em 1964, essa foi revista várias vezes, sendo a última em outubro de 2000, na Escócia, e não em Tóquio, onde ocorreu a primeira revisão em 1975, entre outras nãoconformidades mencionadas ${ }^{(1: 7-8)}$.

Os princípios fundamentais nessa versão não mais são tratados na forma de capítulo com artigos, mas com um texto 
introdutório na forma de tópicos, logo após o preâmbulo. Passou a contemplar de forma mais abrangente alguns pontos específicos em relação ao exercício da enfermagem. O que antes era exposto de maneira não tão bem detalhada passou a ser mais bem explicitado. Exemplos disso são as seções do capítulo l, que tratam dos direitos, responsabilidades, deveres e proibições em relação à profissão; a pessoa, família e coletividade; as relações com a equipe interdisciplinar; com as organizações da categoria e a organização empregadora.

Contempla ainda temas como registros de enfermagem, os quais eram omissos em resoluções anteriores, e traz um capítulo específico para ensino, pesquisa e produção técnico- cientííca, abordando aspectos relacionados à pesquisa com seres humanos. Mantiveram-se os capítulos inerentes às infrações e penalidades, bem com a aplicação dessas últimas.

A seguir, apresentamos, na tabela 1, a estrutura das quatro versões do Código de Ética dos Profissionais de Enfermagem.

Tabela 1 - Estrutura das versões do Código de Ética dos Profissionais de Enfermagem. Salvador, 2011.

\begin{tabular}{|c|c|c|c|}
\hline 1975 & 1993 & 2000 & 2007 \\
\hline $\begin{array}{c}\text { RESOLUÇÃO COFEN } \\
\text { № 09 } \\
04 / 10 / 75\end{array}$ & $\begin{array}{c}\text { RESOLUÇÃO COFEN } \\
\text { No } 160 \\
14 / 05 / 1993\end{array}$ & $\begin{array}{c}\text { RESOLUÇÃO COFEN } \\
\text { № } 240 \\
30 / 08 / 2000\end{array}$ & $\begin{array}{c}\text { RESOLUÇÃO COFEN } \\
\text { № } 311 \\
08 / 02 / 2007\end{array}$ \\
\hline 05 CAPÍTULOS & 09 CAPÍTULOS & 09 CAPÍTULOS & $\begin{array}{l}07 \text { CAPÍTULOS } \\
04 \text { SEÇõES }\end{array}$ \\
\hline 28 ARTIGOS & 100 ARTIGOS & 99 ARTIGOS & 132 ARTIGOS \\
\hline $\begin{array}{c}\text { CÓDIGO DE } \\
\text { DEONTOLOGIA } \\
\text { DE ENFERMAGEM }\end{array}$ & $\begin{array}{l}\text { CÓDIGO DE ÉTICA } \\
\text { DOS PROFISSIONAIS } \\
\text { DE ENFERMAGEM }\end{array}$ & $\begin{array}{l}\text { CÓDIGO DE ÉTICA } \\
\text { DOS PROFISSIONAIS } \\
\text { DE ENFERMAGEM }\end{array}$ & $\begin{array}{l}\text { CÓDIGO DE ÉTICA } \\
\text { DOS PROFISSIONAIS } \\
\text { DE ENFERMAGEM }\end{array}$ \\
\hline $\begin{array}{l}\text { DIRECIONADO } \\
\text { PARA: } \\
\text { ENFERMEIROS }\end{array}$ & $\begin{array}{l}\text { PROFISSIONAIS DE } \\
\text { ENFERMAGEM }\end{array}$ & $\begin{array}{c}\text { PROFISSIONAIS DE } \\
\text { ENFERMAGEM }\end{array}$ & $\begin{array}{c}\text { PROFISSIONAIS DE } \\
\text { ENFERMAGEM }\end{array}$ \\
\hline
\end{tabular}

\section{CONSIDERAÇÕES FINAIS}

Os estudos apontam que, ao longo dos anos, a enfermagem vem conquistando mais espaço no meio social, levando a categoria a novos rumos relacionados ao exercício da profissão, buscando aprimoramento tanto em conhecimentos científicos quanto no exercício dos profissionais legalizado da profissão, através do empenho dos órgãos de classe, a exemplo da Associação Brasileira de Enfermagem, o Sistema Conselhos Federal e Conselhos Regionais de Enfermagem. A busca pela qualidade profissional requer normas a serem seguidas para o benefício do paciente, família e comunidade e do próprio profissional de enfermagem.

Observa-se que o Código de Ética dos Profissionais de Enfermagem flexibiliza a prática profissional no exercício das diversas áreas de atuação da enfermagem, no ensino, na pesquisa, na gerência ou na assistência, de modo que todos os profissionais que exercem a enfermagem deverão conhecer e fazer cumprir os fundamentos e princípios norteadores de uma prática profissional ética, contidos no Código de Ética dos Profissionais de Enfermagem. Deverão, ainda, tê-lo como norteador na orientação e segurança para o exercício da enfermagem com qualidade e dignidade humana.

Assim sendo, pode-se depreender que o Código de Ética dos Profissionais de Enfermagem, em sua versão atual, apresenta um conjunto de normas a serem cumpridas pelo profissional de enfermagem, priorizando e valorizando o cuidado de enfermagem com a pessoa, a família e a comunidade numa perspectiva multidimensional. Isso apontando para o dever do empenho do profissional na melhoria da qualidade da assistência prestada ao paciente, dentro dos preceitos legais, de forma a assegurar o bem-estar do mesmo, partindo de uma visão integral do ser humano.

Nesse sentido, é necessário que todos os profissionais de enfermagem tenham conhecimento do inteiro teor do Cepe, ao qual estão submetidos todos os profissionais de enfermagem no exercício da profissão, como um postulado ético para o bom comportamento profissional e a melhor conduta com nossos pacientes.

\section{Referências}

1. Oguisso T, Takashi MH, Freitas GF. Código de Ética dos Profissionais

de Enfermagem: Histórico e Atualidades. In: Freitas GF, Oguisso

T. Ética no contexto da prática de Enfermagem. Rio de Janeiro:

Medbook; 2010.

2. Narchi NZ, Secaf V. Código de ética profissional e a pesquisa: direitos

autorais e do ser humano. Rev Paul Enf, 2002; 21(3):227-33.

3. Oguisso T. Histórico dos Códigos de Ética de Enfermagem no Brasil. In:

Oguisso T, Schmidt MJ. O exercício da enfermagem: uma abordagem

ético-legal. 3 ed. Rio de Janeiro: Guanabara Koogan; 2010.

4. Brasil. Diário Oficial da República do Brasil. Lei 5905 de 12 de julho de 1973.

Dispõe sobre a criação dos Conselhos Federal e Regionais de Enfermagem e dá

outras providências. Brasília, julho de 1973, seção 1.
5. Triviños ANB. Introdução à pesquisa em ciências sociais: a pesquisa

qualitativa em educação. São Paulo: Atlas; 2008.

6. Cofen. Conselho Federal de Enfermagem. Resolução Cofen 9/75. In:

Documentos Básicos do Cofen. Rio de Janeiro, Cofen; 1983.

7. Cofen. Conselho Federal de Enfermagem. Resolução Cofen 160/93. In:

Documentos Básicos do Cofen. 4 ed. Rio de Janeiro, Cofen; 1996.

8. Cofen. Conselho Federal de Enfermagem. Resolução Cofen 240/00. In:

Documentos Básicos do Cofen. 6 ed. Rio de Janeiro, Cofen; 2000.

9. Cofen. Conselho Federal de Enfermagem. Resolução Cofen 311/07.

[internet]. [citado em 2011 jul 08].

10. Cofen. Conselho Federal de Enfermagem. Resolução Cofen 51/79. In:

Documentos Básicos do Cofen. Rio de Janeiro, Cofen; 1983. 